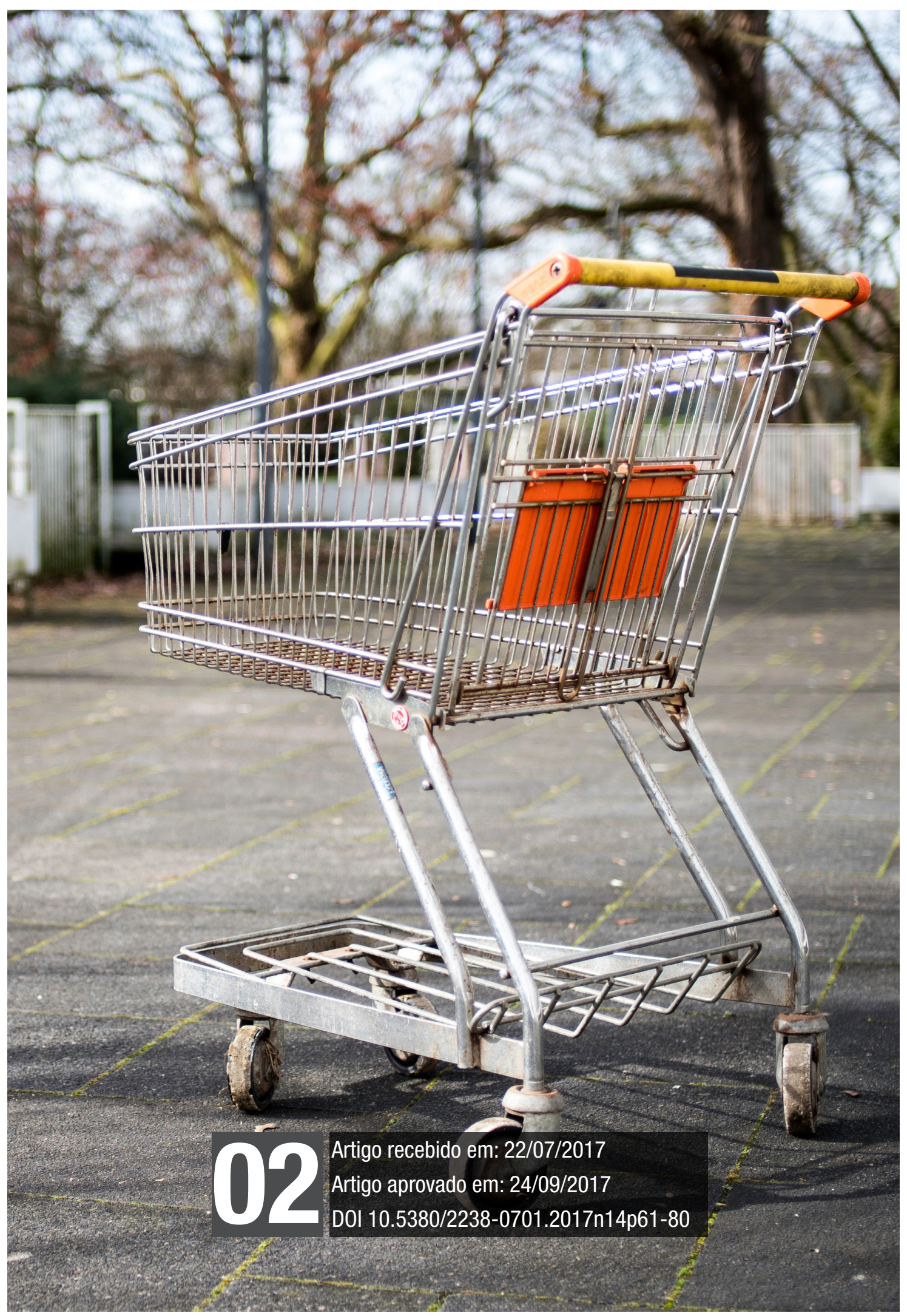


Ambiente. Publicidade. Consumo. Subjetividade.

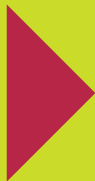




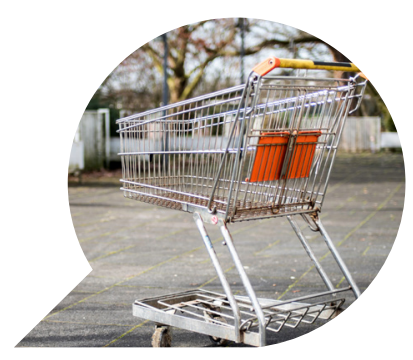

\title{
Consumo, publicidade e crises ambientais: uma análise crítica a partir de um estudo de caso
}

\author{
Consumption, advertising and environmental crises: \\ a critical analysis from a case study
}

Consumo, publicidad y crisis ambientales: un análisis crítico desde un estudio de caso

EDUARDO DE FARIA NOGUEIRA*

SONIA REGINA VARGAS MANSANO ${ }^{\star *}$

Resumo: O ciclo que envolve a exploração de recursos naturais, a produção, a publicidade, o consumo e o descarte têm gerado debates sobre as dificuldades de preservação do meio ambiente no contexto da organização sócio-econômica capitalista vigente. O presente artigo buscou problematizar, especificamente, o descarte e a destinação inadequados de lixo, abordando sua interface com a publicidade e a disseminação do consumo como prática naturalizada. Valendo-se de um estudo de caso, buscou-se dar visibilidade às ações de uma ONG que atua nesse segmento. Como

\footnotetext{
* Mestre em Administração pela Universidade Estadual de Londrina. Docente do curso de Administração da Universidade Norte do Paraná. E-mail: eduardo_f_nogueira@hotmail.com

** Doutora em Psicologia Clínica pela PUC/SP. Docente do Programa de Pós-Graduação em Administração, do Programa de Pós-Graduação em Psicologia e do Departamento de Psicologia Social e Institucional da Universidade Estadual de Londrina. E-mail: mansano@uel.br
} 
resultado parcial, o estudo evidenciou a necessidade de uma análise crítica sobre a efetividade das práticas ambientais em nosso tempo histórico.

Palavras-chave: Crises ambientais; Publicidade; Consumo; Subjetividade; Política.

Abstract: The cycle that involves the exploitation of natural resources, production, advertising, consumption and disposal has generated discussions about the difficulties of preserving the environment in the context of the socio-economic organisation capitalist. This article sought to discuss specifically the discart and inadequate garbage disposal, addressing your interface with the publicity and the dissemination of consumption as naturalized. Using a case study, we sought to give visibility to the actions of an NGO that acts in this segment. As a partial result, the study highlighted the need for a critical analysis on the effectiveness of environmental practices in our long history.

Keywords: Environmental crises; Advertising; Consumption; Subjectivity; Politics.

Resumen: El ciclo que involucra la explotación de recursos naturales, producción, publicidad, consumo y disposición ha generado discusiones acerca de las dificultades de preservar el medio ambiente en el contexto de la actual organización socio-económica capitalista. Este artículo busca discutir específicamente el desecho inadecuado de la basura, abordando su interfaz con la publicidad y la difusión del consumo que se producen de una manera naturalizada. Mediante un estudio de caso, se buscó dar visibilidad a las acciones de una ONG que actúa en este segmento. Como resultado parcial, el estudio puso en relieve la necesidad de un análisis crítico sobre la efectividad de las prácticas ambientales en nuestro momento histórico.

Palabras clave: Crisis ambientales; Publicidad; Consumo; Subjetividad; Política. 


\section{Introdução}

A exploração predatória da natureza e a busca incessante pelo desenvolvimento econômico têm levado a alguns questionamentos acerca da tensa relação entre o homem e a natureza. Se, por um lado, os avanços científicos e tecnológicos incorporados no processo produtivo ao longo dos dois últimos séculos proporcionaram um desenvolvimento econômico e material jamais visto na história humana, por outro, o desenvolvimento socioeconômico, a proliferação de centros urbanos, os conflitos sociais e os danos ambientais causados pelo homem têm desencadeado diversas crises socioambientais e colocado em xeque a organização social vigente (BECK, 2011; STENGERS, 2015). Ao final da década de 1960, a problemática ambiental ganhou destaque e se apresentou como ponto crítico na agenda política e econômica global (O'CONNOR, 2002; JACOBI, 2005). Noções como "sustentabilidade" e "desenvolvimento sustentável" passaram a ser definidas e resignificadas sob diversos pontos de vista, buscando alinhar os interesses econômicos com as demandas sociais e a capacidade de renovação da natureza (PIERRI, 2001).

Após a Segunda Guerra Mundial, em virtude do vigoroso desenvolvimento industrial, as formas de produção e consumo ganharam e alteraram significativamente os rumos do capitalismo. Novas demandas surgiram, fazendo com que as indústrias aumentassem cada vez mais seus níveis de produtividade. O consumo de bens e serviços cresceu de forma exponencial, tornando-se uma força central do sistema capitalista contemporâneo. Entretanto, indissociável ao consumo, está a produção incessante de lixo, responsável por agravar ainda mais as crises ambientais.

Partindo desse cenário, a presente pesquisa indagou como a geração de resíduos sólidos contribui para o agravamento do problema ambiental. Por meio de um estudo de caso qualitativo, o objetivo da pesquisa consistiu em analisar as interfaces entre consumo, descarte e sustentabilidade a partir das práticas operacionais de uma ONG (Organização Não Governamental) que atua na coleta, tratamento e destinação de resíduos eletroeletrônicos. Como resultado parcial, verificou-se que estamos diante de um modo insustentável de vida, que necessita urgentemente de um redirecionamento crítico. 


\section{Mídia e consumo: uma face destrutiva}

Ao longo da história, o humano encontrou na transformação da natureza a fonte para suprir suas necessidades. Sua relação com o meio ambiente causou grandes transformações nos ecossistemas. Entretanto, o acúmulo sistemático dessas ações fez com que chegássemos a uma era marcada por relações de produção e consumo cada vez mais exacerbadas, o que tem resultado em elevados níveis de desgaste ambiental. Beck alerta:

A natureza foi subjugada e explorada no final do século XX e, assim, transformada de fenômeno externo em interno, de fenômeno predeterminado em fabricado. Ao longo de sua transformação tecnológico-industrial e de sua comercialização global, a natureza foi absorvida pelo sistema industrial (BECK, 2011, p. 9).

Tal desgaste é particularmente impulsionado pelo modo de produção capitalista que, em larga medida, gera desigualdades sociais e crises ambientais cada vez mais acentuadas (PIERRI, 2001; O'CONNOR, 2002; STENGERS, 2015). Florestas nativas e grande parte da biodiversidade do planeta foram destruídas e substituídas pela urbanização, instalação de grandes indústrias, monocultura e criação de gado, gerando um quadro ambiental avassalador em diversos países do globo. As mudanças climáticas no cenário global e o colapso dos oceanos já não são apenas previsões alarmistas. A exploração desenfreada dos recursos naturais começa, portanto, a demonstrar sua dimensão mais dramática: inundações, secas, poluição do ar, envenenamento dos alimentos com pesticidas, chuva ácida, deslizamento de terras, contaminação dos lençóis freáticos, geração excessiva de lixo, aumento da pobreza e desigualdades sociais, são "manifestações da crise ambiental, que se relacionam diretamente com os padrões produtivos e de consumo prevalecentes" (JACOBI, 2005, p. 236).

Trata-se de evidências concretas, geradas pelo processo de mercantilização da natureza cada vez mais crescente, que passa a incluir, nos cálculos econômicos, diferentes aspectos da biodiversidade global e seus ecossistemas (STENGERS, 2015; BECK, 2011). Nessa perspectiva exploratória, tudo pode se tornar mercadoria: florestas tropicais, plantações, animais, rios e até mesmo o ar que respiramos. A vida tornou-se algo comercializável e absorvido pelas forças de mercado. Trata-se de uma relação que expõe uma face destrutiva cada vez mais evidente em 
nosso tempo histórico e que tem levantado sérios questionamentos sobre as perspectivas de vida para as gerações futuras. O consumo (entendido como desfrute, esgotamento e compra) associado a componentes subjetivos idealizados como o sucesso, a felicidade e o bem-estar tornaram-se um importante dispositivo utilizado por grandes organizações (públicas e privadas) para o desenvolvimento de um sistema político e econômico, que o torna fundamental para impulsionar todo o funcionamento do sistema capitalista.

A disseminação das práticas de consumo, realizada em escala populacional e presente nos enunciados e imagens midiáticos, relaciona a compra com momentos de felicidade, satisfação e prazer. Trata-se de algo capaz de modificar de maneira profunda os modos de vida, os gostos e as aspirações de grande parte da população, dando contornos à chamada sociedade de consumo (BAUDRILLARD, 1995). Nela, fica evidente que as dimensões subjetivas e as experiências sociais de consumo foram muito bem compreendidas e operacionalizadas pelos mecanismos discursivos e práticos que fomentam o capital, sobretudo nas campanhas midiáticas e nas estratégias de marketing da atualidade. Guattari e Rolnik (1996, p. 26) observam: "forças sociais que administram o capitalismo" captaram bem a sua importância e "entenderam que a produção de subjetividade talvez seja mais importante do que qualquer outro tipo de produção, mais essencial até do que o petróleo e as energias" (IDEM). Estamos, assim, diante de uma produção subjetiva, que tem o consumo como seu vetor principal de expansão e reprodução. Dessa forma, os autores mencionam a "produção de subjetividade capitalística" (IDEM, p. 16), a qual envolve a disseminação de valores do mercado em diversos aspectos da cultura, que fomenta a produção de indivíduos deslocados de suas percepções subjetivas e conectados aos imperativos do mercado.

A ênfase em aspectos subjetivos de consumo envolve um universo simbólico espetacularizado e disseminado pelos meios de comunicação de massa, por campanhas de marketing e ferramentas digitais. São peças publicitárias que retratam situações do cotidiano carregadas com logomarcas, enfatizando perspectivas de vida voltadas, por exemplo, às tendências efêmeras da moda, às inovações tecnológicas e ao status. Assim, a sociedade de consumo contemporânea inaugura uma busca pela novidade e por satisfação em curto prazo, estimulando cada vez mais o consumo e o descarte de produtos. 
Desde o início do século XX até os dias atuais, o marketing se desenvolveu e se tornou estratégia central do capitalismo: uma ferramenta fundamental de disseminação dos valores mercadológicos que permeiam a sociedade de consumo contemporânea (RIFKIN, 2001). Precisamente, essa imbricação contemporânea entre o consumo e o bem-estar, tem intensificado a relação entre homem e natureza de maneira desproporcional, gerando sérias crises e uma extensa lista de riscos sociais e ambientais (BECK, 2011; JACOBI, 2005; O'CONNOR, 2002). No século $\mathrm{XXI}$, entretanto, pudemos perceber mais diretamente que tais práticas têm levado a natureza aos limites de sua capacidade de reposição e estamos vivenciando as consequências diretas da degradação da biosfera. Esse cenário de crise demonstra a relevância e urgência de pensar criticamente as bases do consumo na sociedade atual.

\section{A produção de lixo como problema ambiental e político}

Crises ambientais e problemas urbanos são temas debatidos por agendas internacionais e abordados em diversas conferências globais. O estilo de vida consumista, pautado em valores capitalistas, tem causado sérios efeitos colaterais em termos de impactos ambientais e sociais. Entre as principais consequências danosas da sociedade consumista, a produção de lixo se destaca (LAYRARGUES, 2011). Milhares de toneladas de resíduos são diariamente descartados nas cidades. Nos EUA, são gerados um total aproximado de 624,7 mil toneladas de resíduos sólidos por dia. No que se refere aos países emergentes, o Brasil se destaca com uma produção diária de aproximadamente 149,09 mil toneladas de resíduos sólidos, perdendo apenas para a China, sendo ela a maior geradora de lixo entre os países emergentes, somando 520,54 mil toneladas de resíduos sólidos por dia (WORLD BANK, 2012). Todavia, a preocupação mundial com relação ao lixo ainda é ínfima (JACOBI; BESEN, 2011).

Embora os países desenvolvidos sejam os maiores produtores de lixo, eles possuem sistemas integrados mais eficientes e uma maior capacidade de gerenciamento de seus resíduos sólidos. Já, nos países em desenvolvimento, existem sérias dificuldades para garantir um controle de qualidade ambiental de modo eficiente, sobretudo no que se refere a gestão dos resíduos. O sistema de coleta seletiva brasileiro, por exemplo, ainda é muito frágil, não possibilitando que os municípios se capaci- 
tem para gerenciar os resíduos gerados em função do acelerado ritmo de produção, consumo e descarte (JACOBI; BESEN, 2011; LAYRARGUES, 2011). De acordo com dados da ABRELPE (Associação Brasileira de Empresas de Limpeza Pública e Resíduos Especiais), no Brasil, em 2014, a geração total de Resíduos Sólidos Urbanos (RSU) foi de aproximadamente 78,6 milhões de toneladas (ABRELPE, 2014). A maior parte dos resíduos produzidos são jogados em terrenos baldios, ruas, avenidas, córregos e rios, causando diversos danos ambientais: o assoreamento de rios e córregos, o entupimento de bueiros, a destruição de áreas verdes, a proliferação de insetos transmissores de doenças e a poluição da atmosfera.

A situação piora quando se trata de resíduo eletrônico, extremamente problemático em âmbito global. Os lixos eletrônicos mais comuns são aparelhos celulares, tablets, notebooks, baterias, carregadores, fones de ouvido e câmeras filmadoras. Tais itens não se decompõem facilmente na natureza e possuem, em sua composição física, diversos metais pesados, com elementos químicos altamente nocivos ao meio ambiente e prejudiciais à saúde humana (UNEP, 2009). A produção de lixo eletrônico cresce três vezes mais que o resíduo sólido tradicional, sendo um problema cada vez mais evidente em países em desenvolvimento; no Brasil, estima-se que sejam descartados aproximadamente 400 mil toneladas de eletrodomésticos e eletroeletrônicos por ano - o equivalente a 2 quilos por habitante (VIALLI, 2012).

A aprovação, em 2010, da Política Nacional de Resíduos Sólidos (PNRS) em nosso país, estabeleceu um importante marco regulatório e de controle. Entretanto, sua consolidação ainda é frágil uma vez que:

As metas não foram atingidas. [...] vários entraves para a aplicação da lei na prática ainda são notados. [...] de 2010 a 2014, nota-se que a evolução na gestão de resíduos sólidos no país tem sido bastante lenta, apresentando até mesmo uma estagnação em vários pontos, o que impede a plena aplicação da Lei que instituiu a PNRS (ABRELPE, 2014, p. 114).

Os resultados destacados demonstram que, no cenário brasileiro, em se tratando de gestão de resíduos, a situação é preocupante e está muito aquém das propostas e discussões colocadas no plano de governo. $\mathrm{O}$ tratamento do lixo é um problema recorrente em centros urbanos, uma vez que diversos municípios ainda carecem de programas estruturados para destinação adequada dos resíduos sólidos. Além disso, pouco se discute sobre uma reestruturação ou mudanças de hábitos e padrões de consumo. 
Nas próprias bases educacionais, a problematização entre o consumo e a produção de lixo é quase inexplorada (LAYRARGUES, 2011).

Dentre as três dimensões do tratamento de lixo, que envolvem a redução, o reuso e a reciclagem, apenas esta última é discutida mais sistematicamente, fato que evidencia a abordagem reducionista da preservação ambiental, deixando a desejar no questionamento crítico acerca dos valores culturais que sustentam o modo de produção e consumo da sociedade contemporânea. Em parte, isso acontece pelo fato de que a redução e o reuso se confrontam como uma subjetividade capitalística que investe, desejantemente, o novo e o descarte, demonstrando certo mal-estar por objetos que já foram usados por certo tempo ou por outras pessoas.

A importância das práticas cotidianas de preservação, tão bem descritas na própria PNRS, são inquestionáveis. Em seu Art. $9^{\circ}$, ressalta-se que na gestão e gerenciamento de resíduos sólidos, "deve ser observada a seguinte ordem de prioridade: não-geração, redução, reutilização, reciclagem, tratamento dos resíduos sólidos e disposição final ambientalmente adequada dos rejeitos" (BRASIL, 2010). Entretanto, tais práticas ainda carecem de um debate político capaz de enfrentar as adversidades presentes no tema e a divergência de interesses. (PIERRI, 2001; O'CONNOR, 2002). Daí emergem as seguintes questões: Qual a implicação ética e social de fabricantes, difusores midiáticos e consumidores em relação às questões referentes à preservação da natureza? Em um tempo histórico, que atribui grande valor ao consumo, considerando-o um elemento subjetivo fundamental, como problematizar a relação entre homem e natureza? Exitem iniciativas significativas que demonstrem as possibilidades reais de um desenvolvimento sustentável? Diante de tais questões, a pesquisa voltou-se para o estudo de um caso que evidencia as possibilidades e dificuldades de construir um desenvolvimento sustentável em nosso país.

\section{Trajetória metodológica}

Para a realização da etapa empírica desta pesquisa foi selecionada uma ONG que atua na coleta e reciclagem de lixo eletrônico. A ONG está localizada em uma cidade de médio porte no interior do estado do Paraná. Por atuar diretamente com o desenvolvimento de ações relacionadas ao processamento e à destinação de lixo eletrônico, entendemos que a análise das práticas dessa organização proporciona uma discus- 
são relevante, consolidando-se como um caso exemplar. No decorrer do trabalho, foram realizadas entrevistas com o gerente e o fundador, nas quais foram abordadas as percepções dos gestores no que se refere à temática da pesquisa, buscando conhecer o como e o porquê as operações da organização ganharam consistência, dando visibilidade a seus aspectos subjetivos, sustentáveis e políticos. Nesse sentido, uma abordagem qualitativa apresentou-se como um dispositivo analítico relevante, pois envolveu a obtenção de dados descritivos sobre pessoas, lugares e processos interativos, permitindo compreender os fenômenos na perspectiva dos sujeitos participantes (GODOY, 2010).

O processo de investigação empírica teve a duração de aproximadamente seis meses, envolvendo também observações por meio de visitas sistemáticas à ONG e análise de documentos por ela disponibilizados. Os dados coletados foram divididos em três eixos de análise: 1) O consumo contemporâneo, 2) As crises ambientais, 3) As articulações sociais da ONG. Para o presente artigo, apresentaremos os fragmentos referentes ao item dois, que aborda, especificamente, as crises socioambientais na interface da publicidade com os efeitos da produção de resíduos eletrônicos.

\section{Resultados e discussões: \\ Relato de uma experiência de destinação de lixo eletrônico}

Fundada no ano de 2008, a ONG analisada nasceu de uma iniciativa de seu fundador. Com formação profissional no ramo de informática, ele sempre esteve envolvido com atividades correlacionadas à tecnologia da informação. Ao longo de alguns anos trabalhando com acessórios e componentes eletroeletrônicos, ele percebeu que muitos computadores e aparelhos tecnológicos eram constantemente descartados, por vezes, em condições ainda passíveis de reaproveitamento. $\mathrm{O}$ fundador da ONG viu nessa deficiência da cidade e região uma oportunidade de colocar em prática algumas de suas ideias e inquietações. Assim, ele fundou a ONG que se ocupa do conserto de produtos eletroeletrônicos descartados e considerados obsoletos, além de atuar na destinação adequada dos componentes impossíveis de serem reaproveitados, fazendo do lixo eletrônico sua principal fonte de geração de trabalho e renda.

A ONG conta com uma licença ambiental de operação específica para lixo eletrônico, concedida pelo Instituto Ambiental do Paraná (IAP), e possui locais apropriados para o armazenamento desse tipo de material. Ela trabalha também em parceria com a mídia para a conscientização da 
população quanto aos riscos, consequências e danos causados pelo descarte indevido de lixo e resíduos eletrônicos. Sua missão consiste em:

dar destino ecologicamente correto ao lixo eletroeletrônico e assim, contribuir para o desenvolvimento sustentável. Nossa visão é ser referência nacional em reciclagem e destinação do lixo eletroeletrônico e ainda, servir de exemplo para atitudes mais sustentáveis (ONG, 2016).

A ONG conta, atualmente, com 15 funcionários registrados, atuantes em diferentes setores e funções. Entre suas práticas operacionais, destacamos dois momentos fundamentais: inputs e outputs, sendo que os inputs são as práticas que permeiam as etapas iniciais de entrada de insumos para sua operacionalização e os outputs, as práticas de saída. Na Figura 01 pode-se visualizar o detalhamento das operações da organização.

Figura 1: Fluxo operacional: práticas da ONG

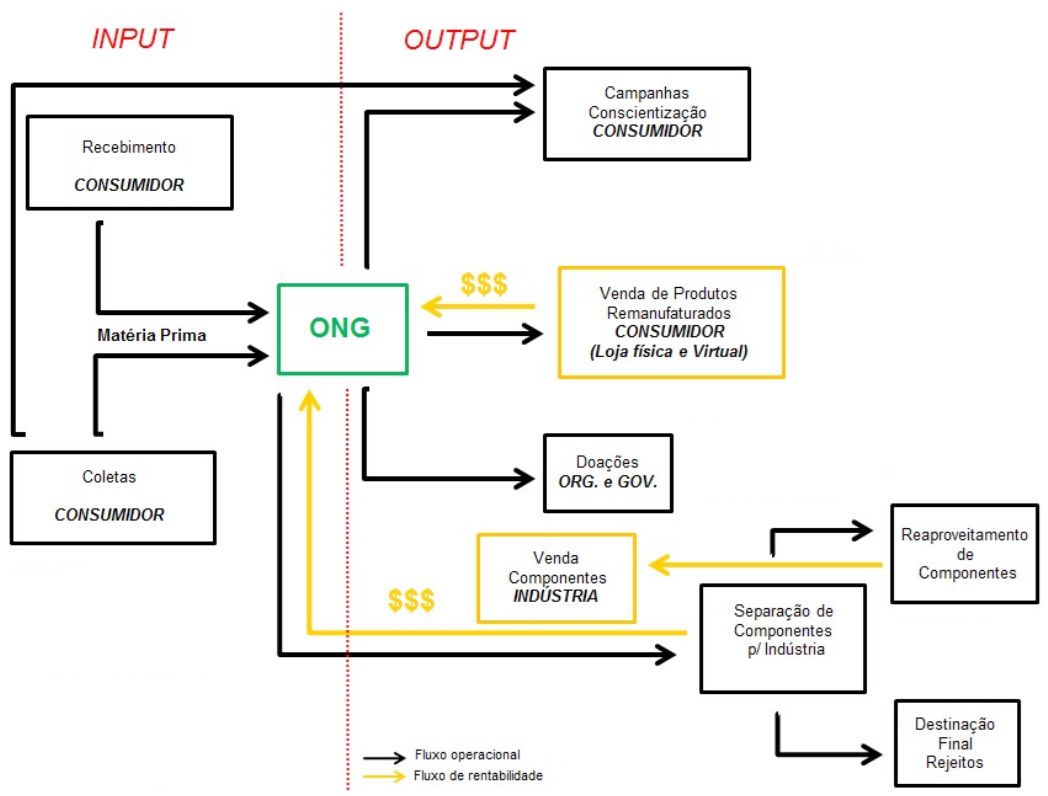

Fonte: Elaborado pelos autores.

No que se refere aos inputs, a ONG recebe os resíduos eletroeletrônicos de duas formas: por intermédio de consumidores que necessitam destinar resíduos eletrônicos considerados obsoletos e por 
meio de campanhas de coletas divulgada por suas mídias sociais (blog, website e facebook) que estimulam pessoas e empresas a levarem os equipamentos até as instalações da ONG. Quanto aos outputs, a organização atua em diversas frentes de venda e distribuição por meio de mídias sociais, eventos divulgação e conscientização sobre os problemas gerados pela produção de resíduo eletroeletrônico. Além disso, a ONG realiza campanhas de doação de produtos remanufaturados para instituições da sociedade civil e governamentais. A ONG conta ainda com uma loja física de onde extrai seu faturamento, como pode ser visualizado na Imagem 1.

Imagem 1 - Loja da ONG: Produtos reaproveitados edisponíveis para venda

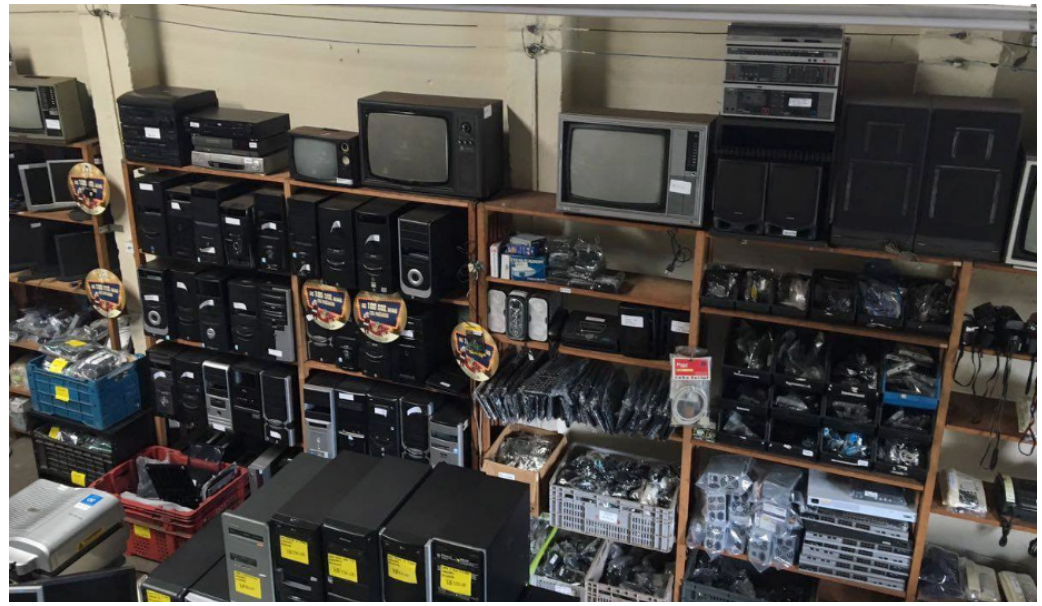

Fonte: Mídias sociais da ONG, 2016.

Na loja, são disponibilizados produtos recuperados a preços acessíveis, fornecendo garantias sobre o produto. Outra importante fonte de rentabilidade da ONG refere-se aos componentes reaproveitados e enviados para diversas indústrias de manufatura. Alguns elementos como cobre, ouro e prata, são separados e enviados para fabricantes de outros estados do país. Tais componentes serão reaproveitados em outras cadeias produtivas. Com base nesse breve panorama histórico da instituição apresentaremos, em seguida, a análise dos dados coletados nas entrevistas.

No que diz respeito ao posicionamento dos entrevistados sobre as crises socioambientais, o fundador afirma: "a crise existe e eu acredito que ela tende a se agravar. Os rios contaminados, os lençóis freáticos, o 
Aquífero Guarani (que já está sendo poluído); a situação é complexa. Na nossa região, especificamente, e na vida do planeta também. O meio ambiente, não é apenas Londrina, não é Jataizinho, não é Ibiporã, mas tudo; é o planeta todo!". Nessa mesma direção, o gerente complementa: "Existe sim a crise. A poluição ocorre dentro deste 'bolo', eu chamo de 'bolo'; nós somos apenas os enfeites em cima do bolo. Então, tudo o que você fizer vai atingir este bolo. Há televisões, computadores, aparelhos de som; tudo isso envenena: chumbo, cádmio, lítio, uma série de metais que são realmente prejudiciais. Esses produtos, esses 'venenos', vão para a Terra, e da Terra para o lençol freático. Nós estamos em cima do Aquífero Guarani, um dos maiores aquíferos do mundo, e vamos acabar deixando uma 'herança violenta' para nossos netos e bisnetos: o envenenamento. O trabalho da ONG é exatamente minimizar este tipo de envenenamento".

Nota-se, pelos depoimentos, que ambos os entrevistados reconhecem a existência de uma crise ambiental. A constatação da poluição global e local, os danos ao Aquífero Guarani, o envenenamento do solo com metais pesados e a contaminação dos lençóis freáticos - provenientes do descarte inadequado de lixo - são questões de extrema relevância e demonstram algumas consequências negativas da ação do homem na natureza. Nessa direção, cabe resgatar a consideração de Beck (2011, p. 25), que afirma o quanto "dissemina-se a consciência de que as fontes de riqueza estão 'contaminadas' por 'ameaças colaterais'. Isso, de forma alguma, é algo novo, mas passou despercebido por muito tempo”.

A relação direta estabelecida pelos entrevistados entre o descarte inadequado de resíduos eletroeletrônicos e a contaminação dos ambientes naturais, evidencia bem os danos causados pela ação humana à natureza e remete à ideia de uma "produção social de risco" (Idem, p. 23). Conforme assinalado por Beck (p. 25): "cedo ou tarde na história social começam a convergir na continuidade dos processos de modernização as situações e os conflitos sociais de uma sociedade 'que distribui riqueza' com os de uma sociedade 'que distribui riscos"'. Os riscos produzidos cotidianamente pelas organizações e pela população são crescentes. "A produção de material eletroeletrônico é muito grande. Há irresponsabilidade da população, por falta de conhecimento - não vou culpar o cidadão. Mas existe uma falta de conhecimento, falta de informação para as pessoas realmente direcionarem corretamente seus lixos eletrônicos. Ao invés de jogarem no fundo de vale, joguem aqui! Tragam aqui para ONG! Não custa nada, mas não! As pessoas preferem jogar fora do que trazer na $O N G$ ”, observa o gerente. Isso contribui com a produção social cotidia- 
na dos riscos, cada vez mais difíceis de serem mensurados, rastreados e combatidos. Seus efeitos se multiplicam e a degradação ambiental se torna crônica. A ideia de contaminação e de envenenamento, destacada pelos entrevistados, reflete essa dimensão.

O diagnóstico feito pelos entrevistados demonstra a preocupação da ONG em manter um posicionamento crítico perante a complexidade da crise ambiental, desde a esfera local até uma escala mundial. A preocupação com os recursos naturais e com as futuras gerações dá sustentação a um discurso ambientalista engajado e demonstra que a ONG está ciente do seu papel frente à crise socioambiental. Percebe-se essa preocupação também quando os entrevistados mencionam as contribuições da ONG na minimização do envenenamento e na disseminação de práticas ambientais. O gerente assinala: "O problema do meio ambiente é que existem muitas preocupações, muitos focos". Para o fundador: "Tudo tem que ser debatido, analisado, com calma, porque o reflexo é direto com relação à questão ambiental". Destacam, com isso, a urgência em discutir o meio ambiente e direcionar esforços para o enfrentamento da crise socioambiental, uma vez que a mesma envolve uma questão múltipla, complexa e de caráter político.

Mas, quais debates e análises, como assinalam os entrevistados, poderiam ser colocados em evidência? A questão que emerge aqui se refere ao crescimento econômico, identificado com o progresso que, no entanto, continua se impondo como único horizonte concebível. A constatação feita pelo gerente de que existem muitos focos de interesse sobre o debate ambiental retrata a dificuldade, por parte dos agentes envolvidos (organizações públicas, privadas e a população), em abordar a dimensão ambiental como um problema de âmbito público. Tal tema, na visão de Jacobi e Besen (2011, p. 135), "tem se mostrado prioritário desde a Conferência Rio 92, em escala global, tanto nos países ricos quanto nos mais pobres". Os autores assinalam ainda que "desde a Rio92, incorporaram-se novas prioridades à gestão sustentável de resíduos sólidos que representaram uma mudança paradigmática, que tem direcionado a atuação dos governos, da sociedade e da indústria" (IDEM). De acordo com a visão dos entrevistados, entretanto, a atuação dos governos e dos fabricantes demonstra não serem suficientes para cumprir seus papéis.

Em se tratando especificamente da questão do lixo eletrônico, o fundador diz: "Não tem nem coleta efetiva de lixo eletrônico, nem reciclagem. E você vê que já tem uma lei de logística reversa, que já foi promulgada e tem que ser praticada. Mas você não vê prática nenhuma. Na verdade, 
na responsabilidade compartilhada tem que estar todo mundo junto: fabricante, comerciante, consumidor. Por quê? Na verdade, a lei deve atingir um impacto ambiental também. Mas, você não vê ninguém coletando. Pega uma televisão hoje e leva em algum Magazine pra você ver se eles pegam de volta! Leva uma geladeira! Eles não pegam de volta. Não tem um sistema agressivo de coleta". O gerente complementa: "temos leis espetaculares com relação à política reversa, porém não são aplicadas. O governo não cobra dos fabricantes uma destinação final”. As declarações dos entrevistados evidenciam que o problema é maior que a disseminação publicitária das vendas e envolve também o descaso por parte dos fabricantes, comerciantes e governos com relação às iniciativas para minimização e/ou mitigação dos impactos ambientais. Isso ocorre especialmente no que se refere à coleta, destinação final de resíduos sólidos e procedimentos de logística reversa. De acordo com Abramovay, Sperznza e Petitgand:

Contrariamente ao que ocorre quando se trata dos setores em que a logística reversa já opera de forma eficiente no Brasil, a esmagadora maioria dos planos hoje existentes, sejam estaduais, sejam municipais, é vaga, genérica e desprovida de metas quantitativas ambiciosas (ABRAMOVAY; SPERANZA; PETITGAND, 2013, p. 51).

Nesse contexto, referindo-se aos resíduos eletroeletrônicos coletados pela ONG e armazenados nos galpões da organização, o fundador comenta: "aqui tem produtos da Samsung, aqui tem produtos da HP, aqui tem produtos da Apple, tem produtos de todo e qualquer fabricante, que, na verdade, é o seguinte: eles que não tão coletando e por isso que vem pra cá? Agora, me mostra uma coleta efetiva de um fabricante!? Não tem! [...] Como eles veem a ONG? Eu acho que um aluno podia, algum dia, fazer também um trabalho e conversar também com o outro lado. Conversar com o fabricante, conversar com eles: 'ah, mas você sabe da existência da ONG? Sabe que a ONG coleta Intel? Sabe que a ONG coleta Toshiba?' Acer, HP, Philips, Panasonic, Dell: as marcas estão todas aqui. 
Imagem 02 - Lixo Eletroeletrônico coletado pela ONG: Barracão

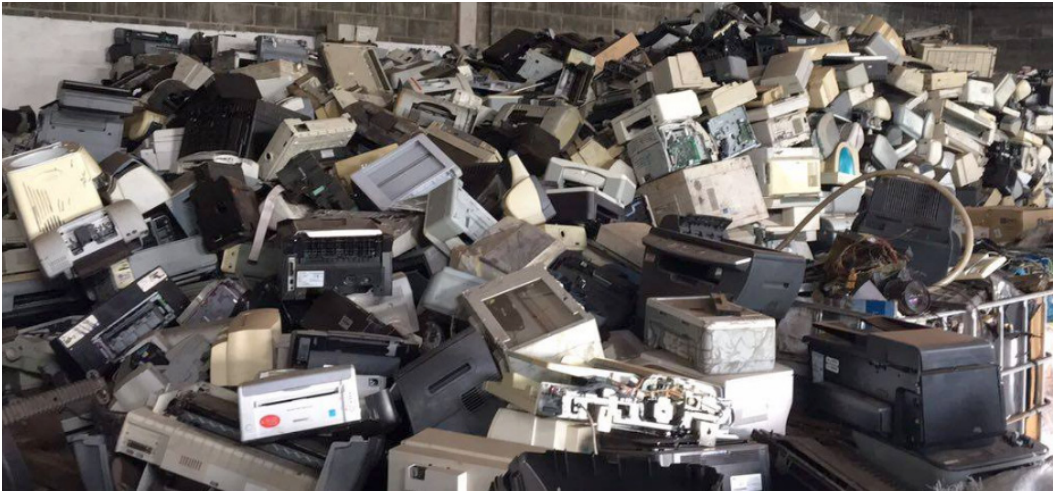

Fonte: Mídias sociais da ONG, 2016.

O último depoimento e a Imagem 02 demonstram a evidente negligência dos fabricantes, bem como a falta de interesse pela coleta ou destinação correta do lixo produzido. Afinal, cabe questionar: A quem interessa a logística reversa? Diz o fundador: "aqui, o comerciante é omisso e o fabricante também". O gerente complementa: "as empresas, os fabricantes, têm que vender muito para manter os empregos e pagar os dividendos para seus acionistas. E acionista não quer saber se está poluindo ou não, ele quer dinheiro, lucro". Ambos evidenciam, portanto, o aspecto econômico sendo utilizado como discurso de interesse em detrimento da dimensão ambiental. Nota-se, também, que população consumidora continua não se visualizando, ou não querendo se colocar, como uma produtora de lixo. O gerente diz: "A irresponsabilidade da população é muito grande. 'Ah eu vou jogar fora isso aqui', jogar fora por quê? Nós somos prisioneiro do planeta, não existe lado de fora! A televisão que você descarta aqui pode afetar a pessoa que mora em Curitiba, que mora em São Paulo. O inverso também é verdadeiro, as mesmas coisas acontecem lá, também afetará aqui”. A dimensão global do problema, assinalada pelo gerente, demonstra o caráter múltiplo que os impactos ambientais ganharam no decorrer do século XX e início do XXI. Os depoimentos evidenciam uma articulação formada por pelo menos três segmentos: fabricantes, mídias e consumidores. Cada um deles, a seu modo, participa do ciclo de exploração predatória da natureza e, sem um debate crítico que envolva governos, empresários, profissionais da mídia e cidadãos, articulados para a reversão do processo, a exploração predatória deve seguir seu curso, impulsionada exclusivamente por taxas de lucro. 


\section{Considerações Finais}

No decorrer do presente estudo, buscamos dar visibilidade à relação intrínseca entre consumo, publicidade e crises ambientais. $\mathrm{O}$ desenvolvimento tecnológico das últimas décadas, embora relevante, deixou suas marcas no excesso de produção de lixo que se impõe como um dos problemas centrais do desenvolvimento econômico sustentável. A problemática decorrente da excessiva geração de lixo eletrônico, demonstrada nos depoimentos dos gestores, evidenciam situações preocupantes do ponto de vista político, econômico, social e ambiental que, no mais das vezes, tendem a ser negligenciadas. Políticas de fiscalização e controle efetivas sobre as empresas poluidoras e geradoras de lixo, implantação de sistemas de logística reversa, melhoria nos processos de produção, consumo e pós-consumo carecem de apoio ou investimento efetivo por parte dessas organizações. A logística reversa, por exemplo, envolve uma cadeia complexa de ações que são similares à cadeia produtiva. Sua condição de possibilidade está atrelada a uma abordagem ética e política do problema, implicando articulações entre segmentos e agentes heterogêneos.

Nessa direção, a ONG analisada representa um percentual ínfimo de efetivação ecológica, frente à produção total de lixo produzido na região, no estado e no país. Em outras palavras, a ONG, com incentivos governamentais e privados mínimos, se posiciona como protagonista local em meio a uma problemática latente nos centros urbanos. Nesse ponto, acompanhamos o questionamento de O'Connor (2002, p. 27): “é possível um capitalismo sustentável?" Parece cada vez mais difícil responder positivamente a essa indagação, tendo em vista os três grandes grupos que participam da consolidação desse cenário: as indústrias diretamente ligadas à exploração da natureza, a publicidade como difusora das práticas de consumo e o consumidor final que tende a naturalizar o descarte e a produção de lixo como práticas que não lhe dizem respeito. De todo modo, os discursos emitidos por cada frente tendem a negligenciar os efeitos adversos dirigidos à natureza, seja pela exploração predatória, seja pela naturalização e estimulação do consumo, seja ainda pela poluição que advém dos resíduos descartados.

Ao final deste estudo, consideramos que a produção de lixo é um tema urgente que precisa ser debatido em diferentes âmbitos, desde os locais até as esferas internacionais. Se instituímos o consumo como um organizador da vida contemporânea, cabe fazer uma análise crítica sobre os efeitos éticos e políticos que tal opção está trazendo para a coletividade. 


\section{REFERÊNCIAS}

ABRAMOVAY R.; SPERANZA, J. S.; PETITGAND, C. Lixo Zero: Gestão de resíduos sólidos para uma sociedade mais próspera. São Paulo: Planeta sustentável - Instituto Ethos, 2013.

ABRELPE - Associação Brasileira de Empresas de Limpeza Pública e Resíduos Especiais. Panorama de Resíduos Sólidos no Brasil 2014. São Paulo: Abrelpe, 2014.

BAUDRILLARD, J. A sociedade de consumo. Lisboa: Edições 70, 1995.

BECK, U. Sociedade de Risco: Rumo a uma outra modernidade. São Paulo: Editora 34, 2011.

BRASIL. Lei n. 12.305, de 2 de agosto de 2010. Brasília: Edições Câmara, 2010.

GODOY, A. S. Estudo de caso qualitativo. In: GODOI, C. K.; BANDEIRA-DEMELO, R.; SILVA, A. B. (Orgs). Pesquisa qualitativa em estudos organizacionais: paradigmas, estratégias e métodos. São Paulo, p. 115-145, 2010.

GUATTARI, F; ROLNIK, S. Micropolítica: Cartografias do Desejo. $4^{\circ}$ ed. Petrópolis: Vozes, 1996.

JACOBI, P. R. Educação ambiental: o desafio da construção de um pensamento crítico, complexo e reflexivo. Revista Educação e Pesquisa FE-USP, São Paulo, 31 (2), p. 302-313, maio/ago. 2005.

JACOBI, P. R.; BESEN, G. R. Gestão de resíduos sólidos em São Paulo: desafios da sustentabilidade. Estudos Avançados, 25, v. 71, p. 135-158, 2011.

LAYRARGUES, P. P. O cinismo da reciclagem. In: LOUREIRO, C. F. B.; LAYRARGUES, P. P.; CASTRO, R. S. (Orgs.). Educação ambiental: repensando o espaço da cidadania. São Paulo: Cortez, 2011.

O’CONNOR, J. ¿Es posible el capitalismo sostenible? In: ALIMONDA, H. Ecología política: Naturaleza, sociedad y utopia. Buenos Aires: CLACSO, p. 27-52, 2002.

PIERRI, N. El Proceso histórico y teórico que conduce a la propuesta del desarrollo suntentable. In: PIERRI, N.; FOLADORI, G. (Eds.) Sostenibilidad? Desacuerdos sobre el desarrollo sustentable. Montevideo: Trabajo y Capital, 2001.

STENGERS, I. No tempo das catástrofes - resistir à barbárie que se aproxima. São Paulo: Cosac Naify, 2015. 
E-waste to resources: Sustainable Innovation and Technology Transfer Industrial Sector Studies. UNEP DTIE. 2009.

VIALLI, A. Seu computador velho vale dinheiro. Guia Exame de Sustentabilidade. São Paulo. Abril, Nov. 2012.

WORLD BANK. What a waste: A global review of solid waste management. Washington, DC, 2012. 